\title{
A Volatility Analysis of Agricultural Commodity and Crude Oil Global Markets
}

\author{
Jamel Trabelsi ${ }^{1,2}$, Mohamed Mehdi Jelassi ${ }^{1}$, Gaye Del Lo $^{3}$ \\ ${ }^{1}$ Department of Quantitative Methods \& LEFA, IHEC Carthage, Carthage University, Tunis, Tunisia \\ ${ }^{2}$ BETA, Strasbourg University, Strasbourg, France \\ ${ }^{3}$ BETA, Loraine University, Nancy, France \\ Correspondence: Mohamed Mehdi Jelassi, IHEC Carthage, 2016 Carthage Présidence, Tunis, Tunisia.
}

Received: December 20, 2016

Accepted: January 3, $2017 \quad$ Available online: January 23, 2017

doi:10.11114/aef.v4i2.2086

URL: http://dx.doi.org/10.11114/aef.v4i2.2086

\begin{abstract}
The purpose of this study is to provide insights on volatility features of major agricultural commodity global markets. In order to achieve this, we estimate the volatility in the global markets of crude oil and four main agricultural commodities, namely rice, wheat, cotton and coffee over the period 1980:2014. We also investigate the nexus between the volatilities in these global markets. More precisely, we first model the volatility of agricultural commodity and crude oil markets based on the GARCH methodology. Second, we assess the risk in these global markets by the Value-at-Risk technique. Finally, we evaluate the co-movements between returns in agricultural commodity and crude oil markets by the copula methodology. Our empirical findings reveal that, unlike in the financial market, upside shocks in the agricultural market tend to increase volatility more than downside shocks do. In addition to that, risk in global agricultural commodity markets turned out to be high and little evidence in favor of interdependence between these markets is found. Moreover, the co-movement between agricultural commodity market risk and oil prices is detected for recent years only and little evidence is found for the whole sample period.
\end{abstract}

\section{JEL Classification: O13, C01, C08}

Keywords: agricultural market, energy market, volatility, value-at-risk, co-movement, copula

\section{Introduction}

Risk is an inherent part of agricultural activity and its impact on the growth of any economy can be very important. Today, hundreds of millions of tons of agricultural products are traded worldwide rendering agriculture not to be restricted to rural areas only but to be extended to receive financial considerations as well. More precisely, many agricultural products are seen as an effective way to diversify investment and hedge against inflation. As a result, agricultural commodity markets have been experiencing a massive inflow of investment rendering these products investment assets. Hence, agricultural commodity prices not only are they very sensitive to production which is very dependent on input prices, climatic factors, energy prices, etc., but are also dependent on the interests of the financial actors interfering in agricultural commodity markets. According to Clapp (2014) global markets for agricultural commodities have been subject to growing financialization, resulting in a remarkable increase in the number and type of financial actors involved in global agrifood commodity chains. In fact, banks and other traditional financial institutions, pension funds and hedge funds are increasingly engaging in commodity and farmland investments. This ongoing financialization process of agricultural commodities certainly contributed to the rise in volatility of food and agricultural commodity prices over the past decade (Heltberg, Hossain, Reva \& Turk, 2013).

Prices of main agricultural products such as rice, cotton and wheat were stable until 2006, after which exceptional high levels were reached. In fact, the 2008 global food crisis was characterized by new record highs and more volatile prices. The resulting high levels of volatility raised the need to adequately investigate such a phenomenon in hopes of coping efficiently with it. In particular, understanding these price fluctuations is essential for any developing economy and especially for those that depend on importing basic agricultural products or rely on exporting specific agricultural commodities. As Stigler (2011) emphasized, a good grasp of such market volatilities as well an appropriate assessment of risk in these markets can undoubtedly help such economies design adequate policies that take into consideration the 
dynamics of the globalized markets.

The post-crisis fluctuations in agricultural commodity prices were also attributed to several other factors. Abbott, Hurt and Tyner (2011), Gilbert (2010) and Baffes (2007) claim that in addition to unfavorable weather conditions, depreciation of the dollar, volatile fuel prices coupled with high intention to increase biofuel production contributed considerably to the post-crisis fluctuations in the agricultural markets. This eventual co-movement between international energy prices and international agricultural commodity prices has also been debated in energy and agricultural economics during the last years (Zilberman, Hochman, Rajagopal, Sexton \& Timilsina, 2013). Hence, investigating the interdependence between agricultural commodity and oil global markets can also provide us with further evidence on the factors that may affect volatility and risk in agricultural commodity global markets.

The aim of this study is to analyze the volatility features of major agricultural commodity global markets during the last three decades. First, we consider four most commonly traded agricultural commodities in global markets, namely, rice, wheat, coffee and cotton. Later, we apply the symmetric and the asymmetric Generalized Autoregressive Conditional Heteroskedastic $(\mathrm{GARCH})$ methodologies to analyze the volatility of these commodities. In fact, the GARCH models have been extensively used to analyze volatility in the field of finance. According to Stigler (2011), the GARCH family models can be appropriately applied to estimate volatility in the agricultural commodity markets, given the ongoing financialization process and the specific features characterizing prices in these markets. In particular, agricultural commodity prices tend to be highly persistent and volatile. Second, the agricultural market risk is quantified based on the Value-at-Risk technique. Third, the interdependence between returns in the agricultural markets are first analyzed and then tested if they are linked to fluctuations in the crude oil global market. Hence, this study does not only contribute to the recent empirical literature by analyzing the volatility of agricultural commodity and crude oil global markets but also by investigating the risk nexus between these markets. Our results reveal that agricultural markets are indeed very volatile. The wheat market is found to be the less volatile, whereas the coffee market is found to be the most risky one. Moreover, unlike in the financial markets, agricultural commodity global markets become more volatile in response to upside shocks than to downside ones. In addition to that, little evidence in support of crude oil prices mutually affecting agricultural commodity global market prices is found. However, evidence in support of a stronger co-movement of agricultural commodity and oil prices is detected for the last decade.

The rest of the paper is organized as follows: In the following section a literature review is provided, after which the data and methodologies used are described. Later the results obtained are discussed and finally concluded.

\section{Literature Review}

Generally, volatility refers to unexpected price movements. Sigler (2011) discussed the application of GARCH family models to study volatility of agricultural commodity markets. He emphasized that volatility clustering has been widely observed in storable agricultural commodity prices. In other words low price volatilities tend to follow low price volatilities and high price volatilities tend to follow high price volatilities. This phenomenon can be accurately described by the Autoregressive Conditional Heteroskedastic (ARCH) model, first introduced by Engel (1982) and was later generalized by Bollerslev (1986) giving rise to the GARCH model. The main idea is to allow the conditional variance to depend on values of previous shocks and on its own past values. In addition to that, Stigler (2011) claimed that it is possible that positive and negative shocks have different effects on price volatility of storable agricultural commodities. He suggested that such an asymmetric effect can be measured using the Exponential GARCH (EGARCH) model of Nelson (1991), or the Glosten, Jagannathan and Runkle (1993) GARCH (GJR-GARCH) model. Several attempts to fit the GARCH family models to study the volatility of agricultural commodity prices exit in the literature. A comprehensive literature review is provided in Brummer, Korn, Schlubler, Jaghdani and Saucedo (2013). In particular, Dahl and Iglesias (2009) introduced an Autoregressive (AR) GARCH functional specification to analyze the effect of spot price volatility on the spot prices of some agricultural commodities and found strong evidence in favor of agricultural commodity spot prices being driven by the expected spot price volatility.

Concerning the nexus between the risk in the oil and that in the agricultural markets, most of the existing literature looked for the directional causalities between such markets, while some focused on the co-movements between crude oil and agricultural commodities. According to Nazioglu, Erdem and Soytas (2013), there is an increased interest in volatility spillover or risk transfer between oil and agricultural commodity prices, however, this literature seems to be still scarce and calls for more attention to the dynamics of the risk transmission.

The relationship between oil prices and agricultural commodity prices was examined in the literature. However the results conveyed are mixed. Among the studies that did not find strong evidence in favor of oil-agricultural commodity prices nexus, we can cite Kaltalioglu and Soytas (2011), Nazlioglu (2011), Reboredo (2012), Ji and Fan (2012), etc.

Kaltalioglu and Soytas (2011) studied the volatility spillover among oil, food and raw agricultural commodity markets over the period 1980 to 2008. Based on their causality analysis, they found no evidence in support of a causality relation 
running from the oil to the food and raw agricultural commodity markets. Nazlioglu (2011) looked at the relationship between world oil prices and three agricultural commodity prices namely, wheat, corn and soybeans over the period 1994 to 2010. The neutrality hypothesis is found to be valid only based on the linear causality analysis. However, strong evidence in support of a non-linear causality running from oil prices to corn and soybeans was detected. Reboredo (2012) found evidence in support of the neutrality of agricultural commodity markets to the world oil prices. Based on several copula models with different conditional dependence structures and time-varying dependence parameters, for the period 1998 to 2011, the prices of corn, soybean and wheat were found to be weakly dependent on oil prices. Ji and Fan (2012) found that crude oil market had minor volatility effects on non-energy products market which includes agriculture and metals. However, this relation was amplified after the 2008 crisis. In particular, they showed that the impact of the crude oil market on other commodity markets was significant when the crude oil prices were at higher levels.

Meanwhile, many other studies found evidence in support of agricultural commodity prices being explained by oil prices: Baffes (2007), Saghaian (2010), Nazlioglu and Soytas (2012), Nazlioglu et al. (2013), Gozgor and Kablamaci (2014), Wang, Wu and Yang (2014), etc.

Baffes (2007) found evidence in support of the interdependence between energy prices and agricultural commodity market over the period 1960 to 2005 . He argued that high energy prices do not only result in high production costs of food products but also encourage the production of biofuels as substitutes. Consequently, demand for crops increases and more pressure will be exerted on energy prices resulting in further escalation of prices. Hence, crude oil prices can clearly be considered as a potential determinant of food prices. Saghaian (2010) found strong correlation among prices of crude oil, ethanol, wheat, corn and soybeans over the period 1996 to 2008, but the evidence for a causal link from oil to commodity prices is mixed. Nazlioglu and Soytas (2012) found strong evidence in favor of a significant and positive impact of oil price increases on 24 world agricultural commodity prices (except in the case of cotton and coffee) over the period 1980 to 2010. They also reported that a depreciation of the dollar had a positive effect on prices of almost all individual agricultural commodities. Nazlioglu et al. (2013) studied the volatility spillovers between the oil and agricultural commodities (wheat, corn, soybeans and sugar) over the period 1986 to 2011. Based on a causality in variance test and impulse response functions, they found that a shock to oil price volatility was transmitted to agricultural markets only during the post-crisis period. More precisely, for the pre-crisis period, they found no evidence for volatility spillover from oil to agricultural commodities, whereas for the post-crisis period only a unidirectional volatility spillover from the oil to corn prices and a bi-directional spillover between oil-soybeans and oil-wheat were found. Gozgor and Kablamaci (2014) investigated the relationship between crude oil and 29 agricultural commodity prices over the period 1990 to 2013. Taking into account the role of the US Dollar and the perceived global market risks, they found that the oil price had unidirectional and positive impacts on almost all agricultural commodity prices. Wang et al. (2014) investigated the effects of supply and demand of crude oil price shocks on several primary commodities. Using a structural VAR model, they showed that the power of changes in oil prices to explain agricultural commodity price variations increased during the post-crisis period.

\section{Data and Methodologies}

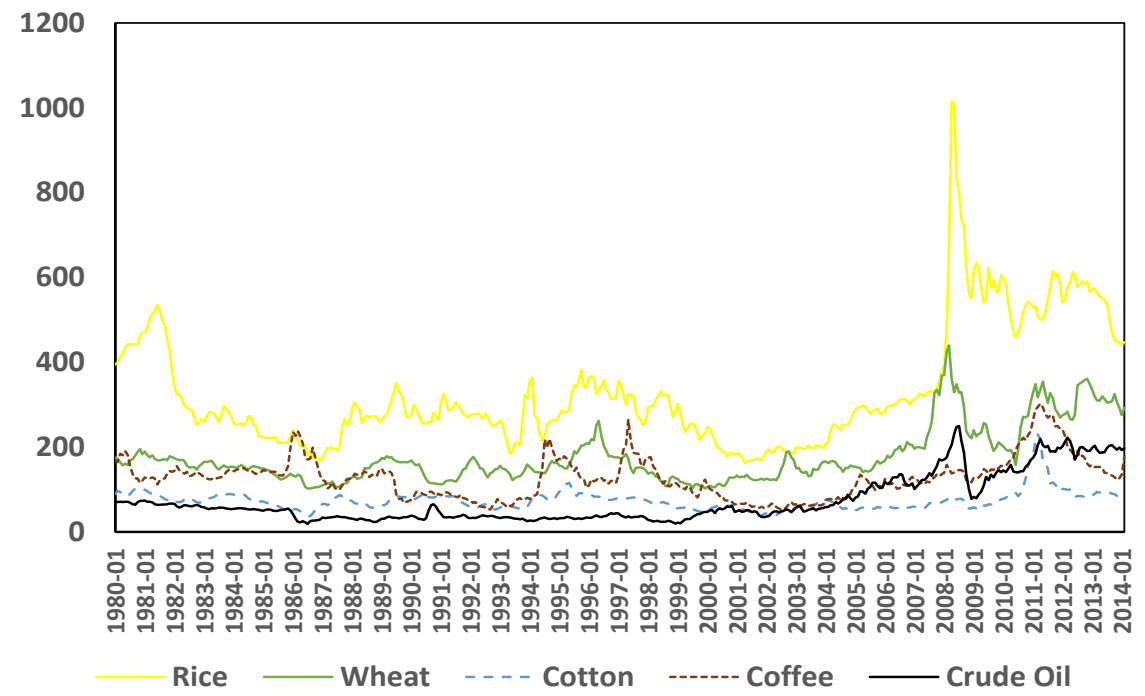

Figure 1. Evolution of agricultural commodity and crude oil prices

International monthly prices of rice (in US dollar per metric ton), wheat (in US dollar per metric ton), cotton (in US cents per pound), coffee (mild arabicas in US cents per pound) and monthly price index (Base 2005, simple average of 
the three spot prices: Dated Brent, West Texas Intermediate and the Dubai Fateh in US dollar per barrel) of crude oil for the period 1980:01 to 2014:02 are obtained from the International Financial Statistics (IFS) database.

It can be easily noticed from Figure 1 that prices of these agricultural products experienced remarkable increases starting from 2005. In particular, the global markets of these agricultural commodities became more volatile. Heltberg et al 2013, claim that since 2006, beside other factors at play, financial speculation has been contributing to the rise in the level and in the volatility of agricultural commodity prices. In fact, during the 2008 food crisis prices of these agricultural commodities reached historically high records. Between mid-2005 and mid-2008, the international price of rice, wheat, cotton and coffee surged by $250 \%, 190 \%, 48 \%$ and $46 \%$ respectively. Moreover, the international price of rice and that of wheat seem to move together with the price of crude oil, suggesting a possible co-movement of prices in global markets of agricultural commodities with international price of crude oil.

In order to investigate the volatility of these global markets, the returns series $r_{t}$ are calculated according to a continuously compounded rate of return as follows:

$$
r_{t}=\ln \left(\frac{P_{t}}{P_{t-1}}\right)
$$

where $P_{t}$ and $P_{t-1}$ are current and previous period prices respectively. The return series are depicted in Figure 2.
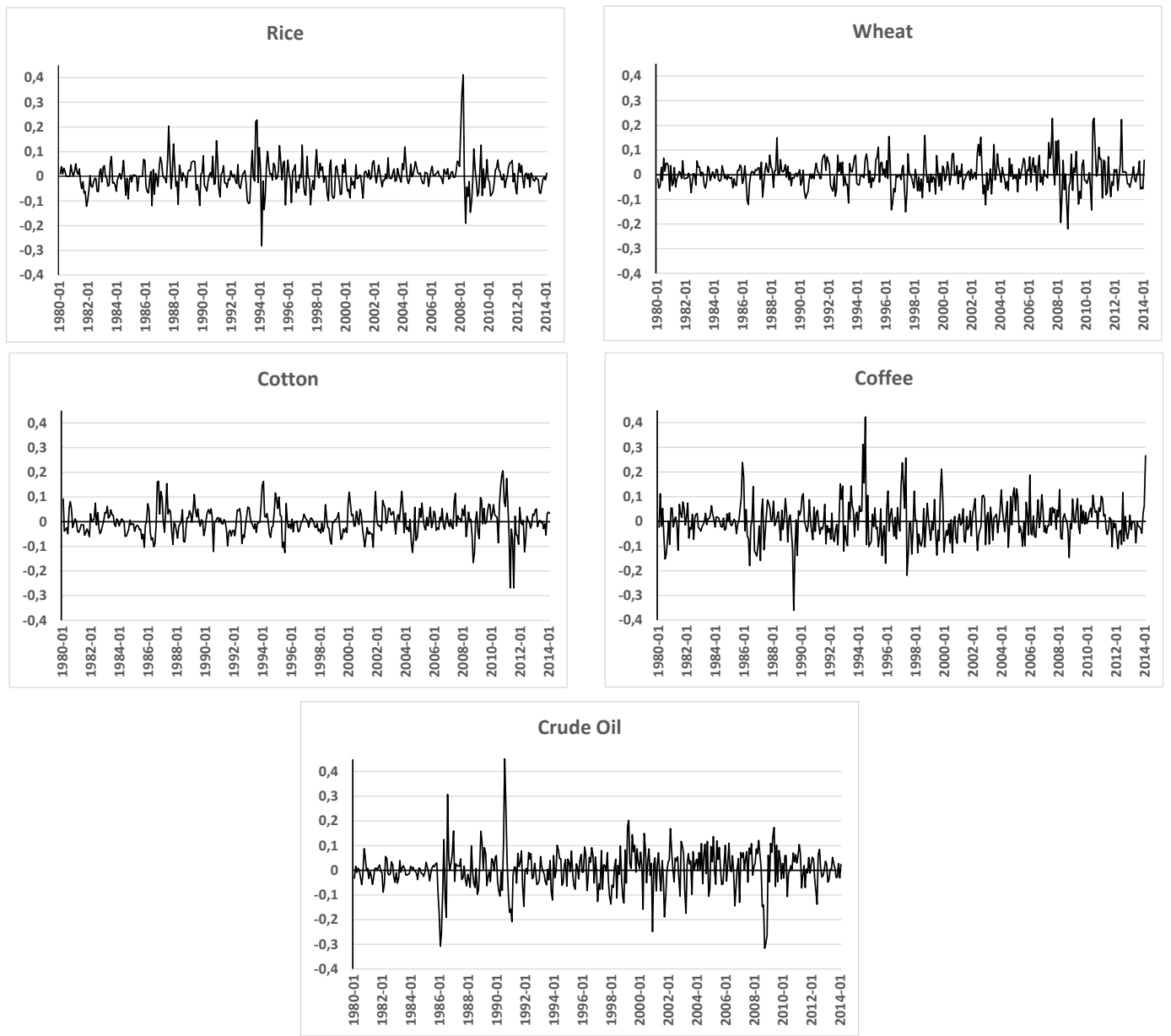

Figure 2. Monthly returns of agricultural commodities and crude oil

Further exploration of the data based on correlation analysis is performed and the results are provided in Table 1. Evidence in support of a high correlation is detected only for the prices of crude oil and wheat and for the prices of crude oil and rice. 
Table 1. Pearson correlation matrix

\begin{tabular}{|c|c|c|c|c|c|}
\hline & Rice & Wheat & Cotton & Coffee & Crude oil \\
\hline \multicolumn{6}{|c|}{ Log oil and log agricultural prices from 1980 to 2014} \\
\hline Rice & 1.000 & & & & \\
\hline Wheat & 0.796 & 1.000 & & & \\
\hline Cotton & 0.566 & 0.516 & 1.000 & & \\
\hline Coffee & 0.547 & 0.454 & 0.553 & 1.000 & \\
\hline Crude oil & 0.681 & 0.787 & 0.353 & 0.357 & 1.000 \\
\hline \multicolumn{6}{|c|}{ Crude oil and agricultural returns from 1980 to 2014} \\
\hline Rice & 1.000 & & & & \\
\hline Wheat & 0.020 & 1.000 & & & \\
\hline Cotton & 0.041 & 0.088 & 1.000 & & \\
\hline Coffee & -0.025 & 0.163 & 0.039 & 1.000 & \\
\hline Crude oil & 0.013 & 0.073 & 0.138 & 0.041 & 1.000 \\
\hline \multicolumn{6}{|c|}{ Crude oil and agricultural returns from second semester 2002 to 2014} \\
\hline Rice & 1.000 & & & & \\
\hline Wheat & -0.027 & 1.000 & & & \\
\hline Cotton & 0.032 & 0.183 & 1.000 & & \\
\hline Coffee & -0.024 & 0.286 & 0.266 & 1.000 & \\
\hline Crude oil & 0.168 & 0.219 & 0.330 & 0.125 & 1.000 \\
\hline
\end{tabular}

In Table 2, the descriptive statistics for the return series of agricultural commodities and crude oil are provided. The high values of the kurtosis statistic suggest that the distribution of returns have fat tails. In addition, the Jarque-Bera statistic rejects strongly the normality of the unconditional distribution for all series and the Ljung-Box statistic indicates strong evidence of autocorrelation in squared returns. These findings show signs of high degree of persistence in the conditional volatility price returns. Hence, GARCH models can be very suitable to model the time-varying conditional volatility of the considered commodity price returns.

Table 2. Descriptive statistics

\begin{tabular}{llllll}
\hline Variable & Rice & Wheat & Cotton & Coffee & Crude oil \\
\hline Mean & 0.033 & 0.120 & 0.036 & 0.005 & 0.238 \\
Min. & -28.127 & -21.918 & -26.905 & -36.059 & -31.628 \\
Max. & 41.164 & 22.915 & 20.581 & 42.322 & 45.941 \\
Median & 0.000 & -0.209 & -0.157 & -0.390 & 0.583 \\
Std. Dev. & 6.020 & 5.650 & 5.640 & 7.810 & 8.030 \\
Skewness & 1.200 & 0.427 & -0.053 & 0.576 & -0.110 \\
Kurtosis & 8.999 & 2.594 & 2.972 & 3.624 & 4.271 \\
Jarque-Bera & $1500.550^{* * * *}$ & $128.416^{* * *}$ & $154.143^{* * * *}$ & $251.164^{* * * *}$ & $317.738^{* * * *}$ \\
$Q^{2}(15)$ & $103.577^{* * *}$ & $63.415^{* * *}$ & $154.054^{* * *}$ & $33.809^{* * *}$ & $104.969^{* * * *}$ \\
\hline
\end{tabular}

Note: values in percentage; ${ }^{* * *}$ Indicates rejection of the null hypothesis of normality for the Jarque-Bera statistic and the rejection of the null hypothesis of no autocorrelation for the Ljung-Box, $Q^{2}(15)$ statistic, at the $1 \%$ significance level.

The stationarity of each series is investigated by applying the Augmented Dickey Fuller (ADF) test, Philips Perron (PP) test and Kwiatkowski, Philips, Schmidt and Shin (KPSS) test. The results are displayed in Table 3.

Table 3. Unit root tests

\begin{tabular}{lllllll}
\hline & \multicolumn{3}{l}{ Level } & \multicolumn{3}{c}{ First difference } \\
\hline & ADF & PP & KPSS & ADF & PP & KPSS \\
\hline Rice & -2.533 & -2.954 & 2.391 & $-8.343^{* * *}$ & $-13.330^{* * *}$ & $0.101^{* * *}$ \\
Wheat & -2.910 & -2.993 & 3.466 & $-8.023^{* * *}$ & $-15.555^{* * *}$ & $0.087^{* * * *}$ \\
Cotton & $-3.659^{* * *}$ & $-3.551^{* *}$ & 0.538 & $-7.506^{* * *}$ & $-12.052^{* * *}$ & $0.062^{* * *}$ \\
Coffee & -2.955 & -2.936 & 0.762 & $-7.289^{* * *}$ & $-16.160^{* * *}$ & $0.074^{* * *}$ \\
Crude oil & -1.865 & -2.411 & 4.881 & $-8.402^{* * *}$ & $-14.422^{* * *}$ & $0.185^{* * *}$ \\
\hline
\end{tabular}

Note: ${ }^{* * *}$ and ${ }^{* *}$ denote rejection of the unit root at the $1 \%$ and $5 \%$ significance level respectively.

All tests clearly indicate the non-stationarity of the variable series in level except the cotton series. For the first differenced series, all tests indicate stationarity of the variables and hence all series should be correctly considered as $I(1)$ except the cotton series which is $I(0)$.

Our descriptive analysis clearly detects the presence of $\mathrm{ARCH}$ effect in all return series. Hence, the volatilities of the agricultural commodity and crude oil markets can be appropriately estimated using the GARCH family models. More precisely, the GARCH, the EGARCH and the GJR-GARCH model specifications are applied to each return series and the model that best fits the data is selected.

In the GARCH model, the conditional variance is allowed to depend on its past previous values. The general form of the 
$\operatorname{GARCH}(p, q)$ model is given by:

$$
\begin{gathered}
r_{t}=\mu+\varepsilon_{t}, \\
\varepsilon_{t} \sim N\left(0, \sigma_{t}^{2}\right) \text { and } \\
\sigma_{t}^{2}=\omega+\sum_{i=1}^{q} \alpha_{i} \varepsilon_{t-i}^{2}+\sum_{j=1}^{p} \beta_{j} \sigma_{t-j}^{2},
\end{gathered}
$$

where $r_{t}$ is return at time $t, \mu$ is mean value of the returns, $\varepsilon_{t}$ is the error term at time $t, q$ is order of ARCH process, $p$ is order of GARCH process and $\sigma_{t}^{2}$ is the conditional variance at time $t$. Hence, the volatility response to movements in the market is measured by $\alpha_{i}$, whereas the persistency of shocks that were caused by extreme values of conditional variance is expressed by $\beta_{i}$.

In the $\operatorname{EGARCH}(p, q)$ model the conditional variance is given by:

$$
\begin{aligned}
& \ln \sigma_{t}^{2}=\omega+\sum_{i=1}^{q} \alpha_{i} g\left(z_{t-i}\right)+\sum_{j=1}^{p} \beta_{j} \ln \sigma_{t-j}^{2}, \\
& \text { where, } g\left(z_{t-i}\right)=\gamma_{i} z_{t-i}+\delta_{i}\left(\left|z_{t-i}\right|-E\left[\left|z_{t-i}\right|\right]\right),
\end{aligned}
$$

$z_{t-i}$ is a white noise $\left(E\left[z_{t-i}\right]=0, \operatorname{var}\left(z_{t-i}\right)=\sigma_{z}^{2}\right)$ and the parameters $\omega, \alpha_{i}, \beta_{i}, \gamma_{i}$ and $\delta_{i}$ are reals.

Unlike the GARCH model, the EGARCH model allows positive (upside) shocks and negative (downside) shocks to have different effects on volatility. The parameter $\gamma_{i}$ captures the asymmetry performance. This asymmetry in the ARCH process is also captured by the GJR-GARCH model. More precisely, downside shocks tend to increase volatility more than upside shocks do (Angabini and Wasiuzzaman, 2011). The conditional variance in the GJR-GARCH $(p, q)$ model is given by:

$$
\sigma_{t}^{2}=\omega+\sum_{i=1}^{q}\left(\alpha_{i}+\gamma_{i} I_{t-i}\right) \varepsilon_{t-i}^{2}+\sum_{j=1}^{p} \beta_{j} \sigma_{t-j}^{2}
$$

where,

$I_{t-i}= \begin{cases}1, & \text { if } \varepsilon_{t-i}<0 \\ 0, & \text { otherwise }\end{cases}$

Hence, the positive effect is measured by $\alpha_{i}$, while the negative effect is measured by $\alpha_{i}+\gamma_{i}$. In addition, if $\gamma_{i} \neq 0$, the effect is asymmetric. In the two asymmetric models, the persistence of conditional variance is measured by $\alpha_{i}+\beta_{i}$ where larger values indicate greater persistence of market shocks.

All the GARCH models tested included a mean equation according to an Autoregressive Moving Average process of order $m$ and $n$ (ARMA $(m, n)$ ) given by:

$$
r_{t}=\Phi_{0}+\sum_{i=1}^{m} \Phi_{i} r_{t-i}+\varepsilon_{t}+\sum_{j=1}^{n} \theta_{j} \varepsilon_{t-j}
$$

In fact, Achal, Girish, Ranjt and Bishal (2015) and Dahl and Iglesias (2009) showed that AR( $m$ )-GARCH type specifications performed well in modeling volatility of agricultural commodity prices. The model that best described the volatility in each commodity market was selected based on the Akaike information criterion (AIC), the Bayes-Schwartz information criterion (BIC) and the log-likelihood statistics. The no correlation of model residuals was verified by the Ljung-Box test.

The high volatility detected in the considered markets as a result of instable commodity prices called for assessing the risk in these markets. An asset portfolio containing rice or wheat or cotton or coffee is undoubtedly exposed to market risk resulting from price fluctuations. The Value-at-risk (VaR) technique can be applied to such a risky asset in order to quantify loss for each asset/commodity. Generally, the VaR is a statistical measure of the maximum loss in value of a risky portfolio that would be expected to occur due to changes in market prices over a time period for a given confidence interval.

Several variants of VaR approaches exist in the literature. However, for the purpose of this study the Gaussian method, the Cornish-Fisher approximation or the so called modified VaR and the historical method are employed. The efficiency of the VaR estimates depends on the correct approximation of the return series distribution. The Gaussian method, for instance assumes that $L(l) \sim N\left(\mu_{L(l)}, \sigma_{L(l)}^{2}\right)$, where $L(l)$ is the loss function over a time period $l$ and $\mu_{L(l)}, \sigma_{L(l)}^{2}$ denote respectively the mean and the variance for this loss distribution. The VaR for a confidence level $\alpha$ can be given then by:

$$
P\left(L(l) \leq-V a R_{l, \alpha}\right)=\alpha .
$$

Letting $\varnothing$ be the cumulative distribution function of a standard normal (8) becomes $\varnothing\left(\frac{-V a R_{l, \alpha}-\mu_{L(l)}}{\sigma_{L(l)}}\right)=\alpha$.

Hence, $\emptyset^{-1}(\alpha)=\frac{-V a R_{l, \alpha}-\mu_{L(l)}}{\sigma_{L(l)}}$ and $\emptyset^{-1}(\alpha)$ is the $\alpha$-quantile of $\emptyset$. 
By symmetry we have $\emptyset^{-1}(\alpha)=-\emptyset^{-1}(1-\alpha)$, therefore

$$
\operatorname{VaR}_{l, \alpha}=-\mu_{L(l)}+\sigma_{L(l)} \emptyset^{-1}(1-\alpha) .
$$

In fact, the Gaussian method is efficient when the return series is normally distributed, whereas, the Cornich-Fisher is more appropriate when the return series is skewed or/and has excess kurtosis. The Cornish-Fisher method, as described in Racicot and Théoret (2006), provides a measure of risk that accounts for fat tails and asymmetry for asset returns. This method takes into account higher moments, skewness and kurtosis and approximates percentiles of non-Gaussian distributions based on Taylor approximation. Hull (2000), provides this approximation up to the third moment of the distribution as,

$$
\emptyset^{-1}{ }_{\alpha}(S, K)={\emptyset^{-1}}_{\alpha}+\frac{S}{6}\left[\left(\emptyset^{-1}{ }_{\alpha}\right)^{2}-1\right]+\frac{K}{24}\left[\left(\varnothing^{-1}{ }_{\alpha}\right)^{3}-3 \emptyset^{-1}{ }_{\alpha}\right]-\frac{S^{2}}{36}\left[2\left(\emptyset^{-1}{ }_{\alpha}\right)^{3}-5 \emptyset^{-1}{ }_{\alpha}\right],
$$

where $S$ and $K$ are respectively the skewness and the kurtosis of the considered distribution. If the asymmetry is zero, the formula becomes:

$$
\emptyset_{\alpha}^{-1}(S, K)=\emptyset^{-1}{ }_{\alpha}+\frac{1}{24}\left[\left(\emptyset^{-1}{ }_{\alpha}\right)^{3}-3 \emptyset^{-1}{ }_{\alpha}\right] K .
$$

Then,

$$
\operatorname{VaR}_{l, \alpha}=-\mu_{L(l)}+\sigma_{L(l)} \emptyset^{-1}{ }_{\alpha}(S, K) .
$$

The historical method on the contrary belongs to the non-parametric family methods and makes no assumption regarding the return distribution. It simply assumes that the asset returns in the future will follow the same pattern of past returns.

In order to further enrich the study, multivariate analysis is performed using the copula which can provide additional evidence on the interdependence between two or more variables with arbitrary marginal distributions. The correlation coefficient is generally considered as an appropriate measure of interdependence of asset returns when these follow a multivariate normal distribution. However, the statistical analysis of the return distributions reveals that these distributions are asymmetric and heavy-tailed. In this case, the linear correlation coefficient is not a good measure to describe the interdependence between asset returns. Instead, the copula technique can be a better alternative since it takes into account these different distribution properties. The copula techniques were introduced by Sklar (1959) and are well introduced in Zivot and Wang (2005), Roncalli (2004), Trivedi and Zimmer (2007) and Kharroubi-Rakotomalala (2008).

Formally, copula $C\left(u_{1}, u_{2}\right)$ is a bivariate distribution function with uniform marginal distributions on $[0,1]$, satisfying the following conditions:

1. $C(u, 0)=C(0, u)=0 \quad$ and $\quad C(u, 1)=C(1, u)=1 \quad$ for all $u \in[0,1]$.

2. $C$ is 2-increasing: $\quad C\left(v_{1}, v_{2}\right)-C\left(v_{1}, u_{2}\right)-C\left(u_{1}, v_{2}\right)+C\left(u_{1}, u_{2}\right) \geq 0$, For all $\left(u_{1}, u_{2}\right) \in[0,1]^{2}$; $\left(v_{1}, v_{2}\right) \in[0 ; 1]^{2}$ such that $0 \leq u_{1} \leq v_{1} \leq 1$ and $0 \leq u_{2} \leq v_{2} \leq 1$.

This definition means that $C$ is a distribution with uniform margins.

According to Sklar's Theorem, for any two random variables $X_{1}$ and $X_{2}$, with joint distribution $F_{X_{1}, X_{2}}\left(x_{1}, x_{2}\right)$ and bivariate distribution functions $F_{X_{1}}\left(x_{1}\right)$ and $F_{X_{2}}\left(x_{2}\right)$ there exists a copula function $C$ such that:

$$
F_{X_{1}, X_{2}}\left(x_{1}, x_{2}\right)=C\left(F_{X_{1}}\left(x_{1}\right), F_{X_{2}}\left(x_{2}\right)\right) .
$$

If $C$ is a copula then $F_{X_{1}, X_{2}}\left(x_{1}, x_{2}\right)$ is a bivariate distribution function with margins $F_{X_{1}}\left(x_{1}\right)$ and $F_{X_{2}}\left(x_{2}\right)$. Hence, copulas link the marginal distributions together to form the multivariate distribution function, which in turn can be decomposed into its univariate marginal distributions and a copula, capturing the dependences structure between the two variables.

Many copula families are available in the literature, however, for the purpose of this study we employ the Gaussian, Frank and Clayton copulas. The Gaussian copula is the copula associated with the multidimensional normal distribution. It takes the form:

$$
\begin{array}{r}
C\left(u_{1}, u_{2}, \rho\right)=\emptyset_{G}\left(\varnothing^{-1}\left(u_{1}\right), \emptyset^{-1}\left(u_{2}\right)\right) \\
=\int_{-\infty}^{\phi^{-1}\left(u_{1}\right)} \int_{-\infty}^{\emptyset^{-1}\left(u_{2}\right)} \frac{1}{2 \pi \sqrt{1-\rho^{2}}} \exp \left\{-\frac{x^{2}-2 \rho x y+y^{2}}{2\left(1-\rho^{2}\right)}\right\} d x d y,
\end{array}
$$

where $\varnothing$ is the cumulative distribution function of the standard normal distribution and $\emptyset_{G}\left(u_{1}, u_{2}\right)$ is the standard bivariate normal distribution with correlation parameter $\rho$ restricted to the interval [-1.1]. Whereas, Frank and Clayton copulas allow a larger variety for the dependence structure. First, unlike some other copulas, Frank copula permits 
negative dependence between the marginal distributions. Second, it allows the dependence to be symmetric in both tails similar to the Gaussian and t-Student copulas. Clayton copula on the other hand, has been essentially used to study correlated risks since it exhibits strong left tail dependence and relatively weak right tail dependence. Specifically, the dependence parameter $\theta$ is restricted to the region given by $(0,+\infty)$. Generator and Copula functions for the Frank and Clayton copulas are given in Table 4.

Table 4. Generator and copula functions for Frank and Clayton copulas

\begin{tabular}{ccc}
\hline Copula & $\emptyset(u)$ & $C\left(u_{1}, u_{2}\right)$ \\
\hline Frank & $-\frac{e^{-\theta u}-1}{e^{-\theta}-1}$ & $-\frac{1}{\theta} \ln \left(1+\frac{\left(e^{-\theta u_{1}}-1\right)\left(e^{-\theta u_{2}}-1\right)}{e^{-\theta}-1}\right)$ \\
Clayton & $u^{-\theta}-1$ & $\left(u_{1}^{-\theta}+u_{2}^{-\theta}-1\right)^{\frac{-1}{\theta}}$
\end{tabular}

The copula models are used to investigate the co-movement of agricultural commodity prices with crude oil prices for two different periods. The first period covers the whole sample period, 1980-2014 while the second one covers the second half only, from 2002 to 2014, during which commodity prices increased remarkably.

\section{Results and Discussions}

The models that fit best to describe the volatility in the global markets of rice, wheat, cotton, coffee and oil are given in Table 5. Several conclusions can be drawn. First, for all the considered commodities the GJR-GARCH model specification was dominated, in terms of goodness of fit, by either the $\operatorname{GARCH}(1,1)$ or the $\operatorname{EGARCH}(1,1)$ model specification. Second, the GARCH term $\beta$ turned out positive and statistically significant at all levels for all commodities, indicating that the volatility of returns in these markets are highly dependent on its previous values. In other words, volatility shocks are highly persistent in all markets. Whereas, the ARCH effect measured by $\alpha$ is only significant for rice and cotton, but not for wheat and coffee, suggesting that volatility responses to market movements are significant for only rice and cotton. In addition to that, $\alpha_{1}+\beta_{1}$ in the GARCH model is equal to 0.8996 , closer to 1 , indicating that the persistence of the conditional variance is high in the global market of cotton.

Table 5. Estimation results

\begin{tabular}{|c|c|c|c|c|c|}
\hline & Rice & Wheat & Cotton & Coffee & Oil \\
\hline & $\operatorname{ARMA}(0,1)$ & $\operatorname{ARMA}(0,1)$ & $\operatorname{ARMA}(3,2)$ & $\operatorname{ARMA}(1,0)$ & $\operatorname{ARMA}(1,1)$ \\
\hline \multirow[t]{2}{*}{$\Phi_{0}$} & 0.0041 & 0.0010 & -0.0011 & 0.0002 & $-0.0046^{* * 3 \times}$ \\
\hline & $(0.0012)$ & $(0.0003)$ & $(0.0039)$ & $(0.0195)$ & $(0.0008)$ \\
\hline \multirow[t]{2}{*}{$\Phi_{1}$} & - & - & $-0.5400^{* * * *}$ & 0.2057 & $-0.0792^{* * *}$ \\
\hline & & & $(0.0706)$ & $(0.2404)$ & $(0.0071)$ \\
\hline$\Phi_{2}$ & - & - & $\begin{array}{l}-0.4365^{* * *} \\
(0.0724)\end{array}$ & - & - \\
\hline$\Phi_{3}$ & - & - & $\begin{array}{l}0.3649^{* * * *} \\
(0.0496)\end{array}$ & - & - \\
\hline$\theta_{1}$ & $\begin{array}{l}0.3670^{* * * *} \\
(0.0463)\end{array}$ & $\begin{array}{l}0.2595^{* * * *} \\
(0.0316)\end{array}$ & $\begin{array}{l}1.0806^{* * * *} \\
(0.0467)\end{array}$ & - & $\begin{array}{l}0.3947^{* * * *} \\
(0.0237)\end{array}$ \\
\hline \multirow[t]{2}{*}{$\boldsymbol{\theta}_{2}$} & - & - & $\begin{array}{l}0.9071^{* * * *} \\
(0.0780)\end{array}$ & - & - \\
\hline & $\operatorname{EGARCH}(1,1)$ & $\operatorname{EGARCH}(1,1)$ & $\operatorname{GARCH}(1,1)$ & $\operatorname{EGARCH}(1,1)$ & $\operatorname{EGARCH}(1,1)$ \\
\hline$\omega$ & $\begin{array}{l}-0.5983^{* * * *} \\
(0.2058)\end{array}$ & $\begin{array}{l}-0.1093 \\
(0.0907)\end{array}$ & $\begin{array}{l}0.0002^{* * * *} \\
(0.0001)\end{array}$ & $\begin{array}{l}-0.9438 \\
(0.8628)\end{array}$ & $\begin{array}{l}-0.3961^{\text {**** }} \\
(0.1656)\end{array}$ \\
\hline$\alpha_{1}$ & $\begin{array}{l}0.1278^{* * * *} \\
(0.0695)\end{array}$ & $\begin{array}{l}0.0352 \\
(0.0432)\end{array}$ & $\begin{array}{l}0.1771^{* * * *} \\
(0.0410)\end{array}$ & $\begin{array}{l}0.0923 \\
(0.1112)\end{array}$ & $\begin{array}{l}-0.1020^{* * *} \\
(0.0405)\end{array}$ \\
\hline$\beta_{1}$ & $\begin{array}{l}0.8968^{* * *} \\
(0.0350)\end{array}$ & $\begin{array}{l}0.9803^{* * *} \\
(0.0143)\end{array}$ & $\begin{array}{l}0.7225^{* * *} \\
(0.0546)\end{array}$ & $\begin{array}{l}0.8174^{* * *} \\
(0.1640)\end{array}$ & $\begin{array}{l}0.9242^{* * *} \\
(0.0322)\end{array}$ \\
\hline$\gamma_{1}$ & $\begin{array}{l}0.3922^{* * * *} \\
(0.0739)\end{array}$ & $\begin{array}{l}0.1419^{* *} \\
(0.1058)\end{array}$ & - & $\begin{array}{l}0.4070^{* * * *} \\
(0.1721)\end{array}$ & $\begin{array}{l}0.4922^{\text {**** }} \\
(0.0986)\end{array}$ \\
\hline
\end{tabular}

Note: ${ }^{* * *}$ and ${ }^{* *}$ denote rejection of the null hypothesis at the $1 \%$ and 5\% significance level respectively. Robust standard errors are given between parentheses.

On the other hand the volatility in the global market of crude oil is high and persistent as suggested by the high value of $\alpha_{1}+\beta_{1}$ being equal to 0.8222 .

Third, shocks have asymmetric effect in the global markets of rice, wheat, coffee and oil but not for coffee. The asymmetric coefficient $\gamma_{1}$, for these commodities, is positive and statistically significant at the 5\% significance level, indicating no leverage effect. Hence, unlike in the financial markets our results show strong evidence in support of 
volatility increases being more with price increases than with price decreases just in line with the specific features of storable agricultural commodity markets discussed in Stigler (2011). Consequently, for storable agricultural products, rising prices tend to generate more effect on the volatility than falling prices do. As explained by Stigler (2011), this phenomenon is in accordance with the storage model where the price increase tend to be followed by depletion of stocks and hence an increase in volatility, Beck (2001). Typically, when the actual price is below the level speculators expect to prevail in the next period (downside shock), speculators will store the commodity in order to sell it at a higher price during the next period. On the contrary, when the current price is above the next period's expected value (upside shock), speculators will not store the commodity and prices simply follow the path of the underlying supply shock.

Fourth, the plots of the estimated conditional volatilities given in Figure 3, reveal that the global markets of rice and coffee experienced brief periods of high volatility, whereas the global markets of wheat and cotton experienced relatively slight increases in volatility.
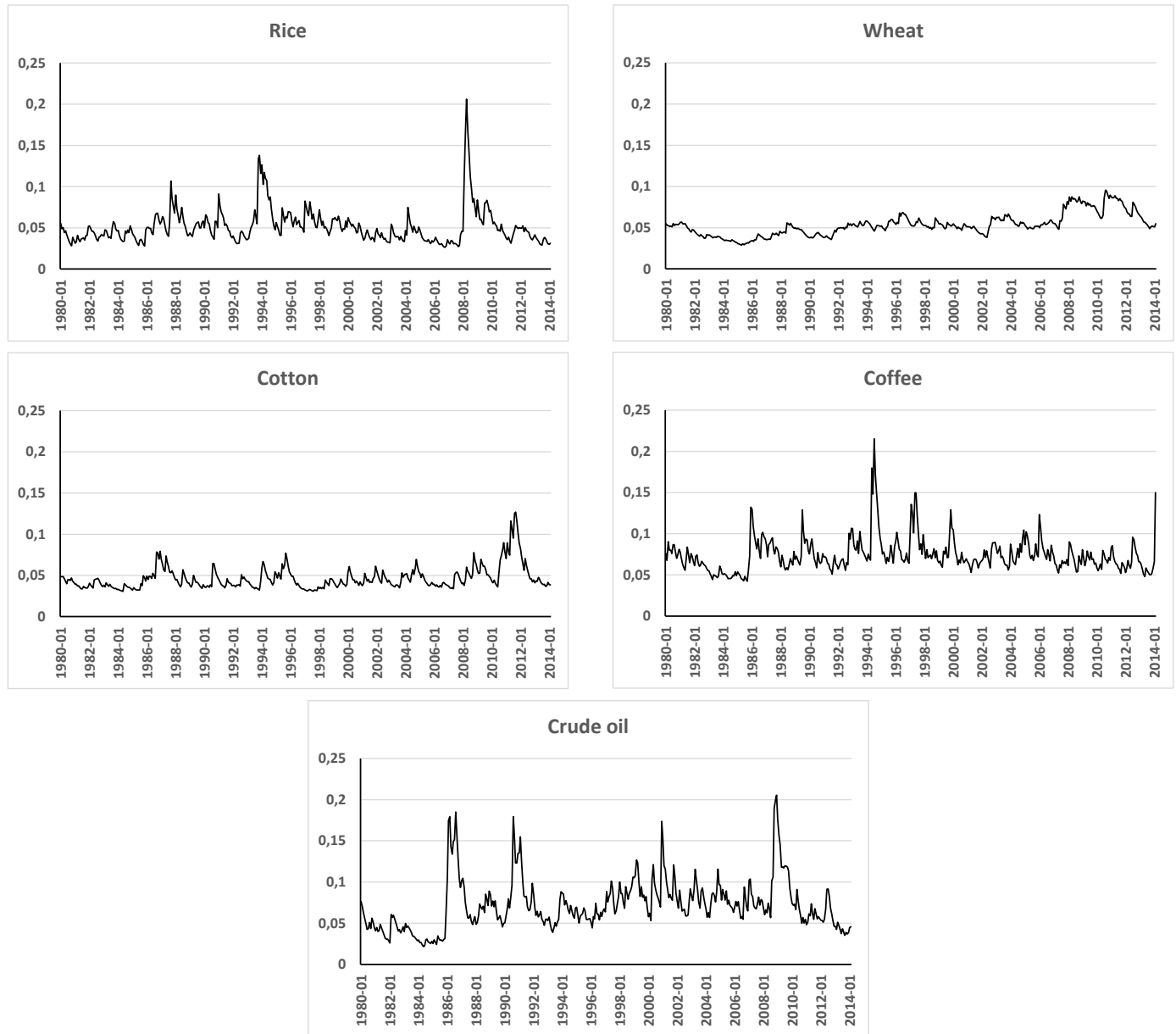

Figure 3. Conditional volatility of agricultural commodity and crude oil returns

Hence, the spikes in the volatility of returns can be explained by sudden increases in the commodity prices, evincing the importance of the role played by speculators in increasing the volatility in the global markets of rice and coffee. Nevertheless, it is worth noting that the 2008 food crisis resulted in a considerable increase in the volatility in the global market of rice only. In addition to that, the wheat market is found to be characterized by relatively more stable volatility, suggesting that speculators intervening in this market tend to have a long-run leveling effect on prices.

Table 6. Value-at-Risk results

\begin{tabular}{lllllll}
\hline & Gaussian & VaR & Modified & VaR & \multicolumn{2}{l}{ Historical VaR } \\
\hline Quantile & 0.95 & 0.99 & 0.95 & 0.99 & 0.95 & 0.99 \\
\hline Rice & 0.09852 & 0.13947 & 0.06533 & 0.18072 & 0.08617 & 0.12141 \\
Wheat & 0.09164 & 0.13010 & 0.08157 & 0.14298 & 0.08214 & 0.14075 \\
Cotton & 0.09231 & 0.13070 & 0.08974 & 0.17236 & 0.08314 & 0.12512 \\
Coffee & 0.12823 & 0.18138 & 0.10918 & 0.20513 & 0.11830 & 0.15827 \\
\hline
\end{tabular}

The VaR estimates for each agricultural commodity are determined by the three methods and results are displayed in Table 6. The maximum loss is highest in the coffee market. Hence the coffee market turned out to be highly risky. According to 
the Gaussian VaR estimate, with probability 0.01 the maximum loss for a long position (one month) of $\$ 1000$ stock of coffee is $\$ 181.380$. This means that, with probability 0.99 the potential loss of holding that stock next month is $\$ 181.380$. For the same probability, the loss is estimated at $\$ 205.130$ by Cornish Fisher approximation. This approach describes better returns distributions (that are asymmetric) than Gaussian method which underestimates it. In fact, Cornish Fisher approximation adjusts the standard deviation to account for skew and kurtosis in the distribution of returns.

The results provided by the VaR calculations show that overall, the risk level is important in agricultural commodity global markets.

The results of the copula models applied to assess the interdependence between returns of agricultural commodities are provided in Table 7. The interdependence is found significant and positive only for wheat-coffee and wheat-cotton pairs.

Table 7. Estimation results of the copulas for agricultural commodities

\begin{tabular}{lllllll}
\hline & \multicolumn{2}{c}{ Gaussian copula } & \multicolumn{2}{c}{ Frank copula } & \multicolumn{2}{c}{ Clayton copula } \\
\hline & $\rho$ & AIC & \multicolumn{1}{c}{$\theta$} & AIC & $\theta$ & AIC \\
Rice-wheat & 0.052 & 3.954 & 0.370 & 3.122 & 0.032 & 6.513 \\
Rice-cotton & 0.049 & 3.421 & 0.215 & 4.697 & 0.045 & 4.197 \\
Rice-coffee & -0.019 & 7.14 & -0.156 & 5.986 & $-0.093^{* *}$ & 1.042 \\
Wheat-cotton & $0.081^{*}$ & 1.393 & 0.350 & 2.850 & $0.098^{*}$ & 1.235 \\
Wheat-coffee & $0.161^{* * *}$ & -1.371 & $0.919^{* *}$ & -1.064 & $0.210^{* *}$ & -1.33 \\
Cotton-coffee & 0.042 & 3.974 & 0.247 & 4.192 & 0.044 & 4.480 \\
\hline
\end{tabular}

Note: ${ }^{* \overline{* *}},{ }^{* *}$ and ${ }^{*}$ denote rejection of the null hypothesis at the $1 \%, 5 \%$ and $10 \%$ significance level respectively.

In fact, only a weak interdependence between returns in the considered agricultural commodity markets is detected. These results suggest that investment is not diversified between these markets. According to portfolio theory, diversification can reduce portfolio risk when correlation is negative between assets. However, for agricultural commodity global markets, the risk management strategy in practice seems to be in favor of concentrating investment in a single or fewer markets.

Table 8. Estimation results of copula models for agricultural commodities and crude oil

\begin{tabular}{|c|c|c|c|c|}
\hline & Oil-rice & Oil-wheat & Oil-cotton & Oil-coffee \\
\hline \multicolumn{5}{|c|}{ A. Estimation results for the period $1980-2014$} \\
\hline \multicolumn{5}{|c|}{ Gaussian copula } \\
\hline$\rho$ & -0.028 & 0.063 & $0.142^{* * *}$ & 0.023 \\
\hline AIC & 5.68 & 2.429 & -0.856 & 6.498 \\
\hline \multicolumn{5}{|c|}{ Frank copula } \\
\hline $\boldsymbol{\theta}$ & -0.344 & 0.384 & $0.777^{* * *}$ & 0.069 \\
\hline AIC & 2.836 & 2.407 & -0.395 & 9.223 \\
\hline \multicolumn{5}{|c|}{ Clayton copula } \\
\hline $\boldsymbol{\theta}$ & 0.036 & 0.107 & $0.175^{* * *}$ & 0.030 \\
\hline AIC & 4.153 & 0.455 & -1.380 & 5.381 \\
\hline \multicolumn{5}{|c|}{ B. Estimation results for the period from the second half of 2002 to 2014} \\
\hline \multicolumn{5}{|c|}{ Gaussian copula } \\
\hline$\rho$ & 0.102 & $0.188^{* *}$ & $0.300^{* * *}$ & 0.096 \\
\hline AIC & 2.618 & 0.131 & -1.790 & 2.834 \\
\hline \multicolumn{5}{|c|}{ Frank copula } \\
\hline $\boldsymbol{\theta}$ & 0.311 & $1.085^{* *}$ & $1.636^{* *}$ & 0.460 \\
\hline AIC & 5.373 & 0.370 & -1.178 & 3.711 \\
\hline \multicolumn{5}{|c|}{ Clayton copula } \\
\hline $\boldsymbol{\theta}$ & 0.138 & $0.252^{* *}$ & $0.321^{* *}$ & 0.123 \\
\hline AIC & 0.968 & -0.733 & -1.970 & 1.735 \\
\hline
\end{tabular}

Note: ${ }^{* * *}$ and $^{* *}$ denote rejection of the null hypothesis at the $1 \%$ and $5 \%$ significance level respectively.

Concerning the interdependence between the energy and agricultural commodity markets, our estimations based on the copula models are reported in Table 8. Our results indicate that, over the whole sample period, the interdependence is found significant for the oil-cotton pair only. It is worth noting that the oil-cotton interdependence measure given by the Gaussian copula is very close to the one given by the linear correlation coefficient, reported in Table 1. However, based on the AIC criterion, the Clayton copula turned out better in describing the co-movement of agricultural commodities and oil prices. The interdependence during the more recent period, is found positive for all pairs and significant for only the oil-cotton and oil-wheat pairs, suggesting little evidence in favor of a tight link between the energy and the agricultural commodity markets.

In particular, oil price fluctuations did not have a strong effect on agricultural market prices and vice versa. Nevertheless, we must admit that considering other traded agricultural commodities that are used in the production of biofuels, such as maize, soybean and sugar, can improve fine-tuning our conclusion on the nexus between the energy and agricultural commodity markets. According to Zilberman et al (2013), the recent increase in biofuel production lead to a 
straightforward increase in volatility of agricultural commodities used in the production of biofuels. This increase in volatility was transmitted to other agricultural markets too. Hence, energy prices drive long-run agricultural price levels and the recent instability in energy markets was transferred to food markets.

\section{Conclusion}

Assessing adequately the risk inherently existing in global agricultural markets can undoubtedly help improving the risk hedging strategies. In this study, the global agricultural market risk is studied based on global market volatility analysis of most commonly traded agricultural commodities, namely, rice, wheat, cotton and coffee, over the period 1980:2014. The volatility nexus between these markets as well as the eventual co-movement between the volatility in crude oil market and volatilities in these agricultural commodity markets are also examined.

Based on the estimates made in this work, several results are reached. First, international prices of agricultural commodities are highly volatile and are likely to react persistently to shocks. However, volatility of returns in the wheat market is found to be more stable than volatility of returns in the rice market, even though both of them are mainly used to serve the same need, feeding human. Hence, regulatory bodies and policies prevailing in the global wheat market seem to be more effective than those prevailing in the global rice market in terms of stabilization of price volatility. Similarly, our analysis provides evidence in favor of volatility being relatively more stable in the cotton global market too.

Second, the asymmetry effect which is positive and statistically significant in most of these global markets, in particular, in that of rice, wheat and coffee, suggests that positive shocks have more effect on volatility than negative ones do, just as predicted by the storage model. The increase in commodity prices tend to deplete stocks and hence increase volatility. This increase in volatility in turn generates greater uncertainty which leads to higher costs of managing risk.

Third, the Value-at-Risk analysis evinced that overall, the risk is important in the agricultural commodity global markets. The coffee global market turned out to be the most risky one in addition to the fact that it was found highly volatile. However, unlike for rice, the 2008 food crisis did not have a significant impact on volatility in the global market of coffee.

Fourth, the copula analysis revealed that there is no strong evidence in support of an interdependence between profits and losses in the agricultural commodity markets, suggesting that diversification strategy may not be commonly adopted by investors in the agricultural global markets to help them hedge against risk. Instead, investment in global agricultural markets tend to be less diversified. However, further analysis in needed in order to determine the optimal decisions made by investors in the agricultural commodity global markets.

Finally, we did not find strong evidence in support of price co-movement between agricultural commodities and crude oil over the study period, suggesting that the international price of agricultural commodities is more dependent on the role played by participating actors within these markets than on the price of crude oil. However, in recent years, evidence in favor of increasing price interdependence among crude oil and agricultural commodities is detected, especially for wheet and cotton.

\section{References}

Abbott, P. C., Hurt, C., \& Tyner, W. E. (2011). What's driving food prices in 2011? Farm Foundation, Issue Report, July 2011.

Achal, L., Girish, K. J., Ranjit, K. P., \& Bishal, G. (2015). Modeling and forecasting of price volatility: An application of GARCH and EGARCH models. Agricultural Economics Research Review, 28(1), 73-82. https://doi.org/10.5958/0974-0279.2015.00005.1

Angabini, A., \& Wasiuzzaman, S. (2011). GARCH models and the financial crisis-A study of the Malaysian stock market. The International Journal of Applied Economics and Finance, 5(3), 226-236. https://doi.org/10.3923/ijaef.2011.226.236

Baffes, J. (2007). Oil spills on other commodities. Resources Policy, 32(3), 126-134. https://doi.org/10.1016/j.resourpol.2007.08.004

Beck., S. (2001). Autoregressive conditional heterroscedasticity in commodity spot prices. Journal of Applied Econometrics, 16, 115-132. https://doi.org/10.1002/jae.591

Bollerslev, T. (1986). Generalized autoregressive conditional heteroscedasticity. Journal of Econometrics, 31(3), 307-327. https://doi.org/10.1016/0304-4076(86)90063-1

Brummer, B., Korn, O., Schlubler, K., Jaghdani, T. J., \& Saucedo, A. (2013). Volatility in the after crisis period-A literature review of recent empirical research. Working Paper No 1, ULYSSES project, EU $7^{\text {th }}$ Framework Programme, Project 312182 KBBE.2012.1.4-05, http://www.fp7-ulysses.eu/, 46.

Clapp, J. (2014). Finacialization, distance, and global food politics. The Journal of Peasant Studies, 41(6), 797-814. https://doi.org/10.1080/03066150.2013.875536 
Dahl, C. M., \& Iglesias, E. M. ( 2009). Volatility spill-overs in commodity spot prices: New empirical results. Economic Modelling, 26, 601-607. https://doi.org/10.1016/j.econmod.2009.01.004

Engle, R. F. (1982). Autoregressive conditional heteroscedasticity with estimates of the variance of the United Kingdom inflation. Econometrica, 50(4), 987-1008. https://doi.org/10.2307/1912773

Gilbert, C. L. (2010). How to understand high food prices. Journal of Agricultural Economics, 61, $398-425$. https://doi.org/10.1111/j.1477-9552.2010.00248.X

Glosten, L. R., Jagannathan, R., \& Runkle, D. E. (1993). On the relation between the expected value and the volatility of the nominal excess return on stocks. Journal of Finance, 48(5), 1779-1801. https://doi.org/10.1111/j.1540-6261.1993.tb05128.x

Gozgor, G., \& Kablamaci, B. (2014). The linkage between oil and agricultural commodity prices in the light of the perceived global risk. Agricultural Economics-Czech, 60, 332-342.

Heltberg, R., Hossain, N., Reva, A., \& Turk, C. (2013). Coping and resilience during the food, fuel, and financial crisis. The Journal of Development Studies, 49(5), 705-718. https://doi.org/10.1080/00220388.2012.746668

Hull, J. (2000). Options, futures, and other derivatives ( $8^{\text {th }}$ edition). Prentice Hall, Boston.

Ji, Q., \& Fan, Y. (2012). How does oil price volatility affect non-energy commodity markets. Applied Energy, 89, 273-280. https://doi.org/10.1016/j.apenergy.2011.07.038

Kaltalioglu, M., \& Soytas, U. (2011). Volatility spillover from oil to food and agricultural raw material markets. Modern Economy, 2, 71-76. https://doi.org/10.4236/me.2011.22011

Kharroubi-Rakotomalala, C. (2008). Les fonctions copules en finance. Publication de la Sorbone, Paris.

Nazilioglu, S., Erdem, C., \& Soytas, S. (2013). Volatility spillover between oil and agricultural commodity markets. Energy Economics, 36, 658-665. https://doi.org/10.1016/j.eneco.2012.11.009

Nazlioglu, S. (2011). World oil and agricultural commodity prices: evidence from nonlinear causality. Energy Policy, 39, 2935-2943. https://doi.org/10.1016/j.enpol.2011.03.001

Nazlioglu, S., \& Soytas, S. (2012). Oil price, agricultural commodity prices, and the dollar: A panel cointegration and causality analysis. Energy Economics, 34, 1098-1104. https://doi.org/10.1016/j.eneco.2011.09.008

Nelson, D. B. (1991). Conditional heteroscedasticity in asset returns: A new approach. Econometrica, 59(2), $347-370$. https://doi.org/10.2307/2938260

Racicot, F. C., \& Théoret, R. (2006). Finance computationnelle et gestion des risques. Presses de l'Université du Québec.

Reboredo, J. C. (2012). Do food and oil prices co-move? Energy Policy, 49, 456-467. https://doi.org/10.1016/j.enpol.2012.06.035

Roncalli, T. (2004). La gestion des risques financiers. Economica.

Saghaian, S. H. (2010). The Impact of the oil sector on commodity prices: Correlation or causation? Journal of Agricultural and Applied Economics, 42(03), 477-485. https://doi.org/10.1017/S1074070800003667

Sklar, A. (1959). Fonctions de répartition à n dimensions et leurs marges. Publications de l'Institut de Statistique de L'Université de Paris 8, Paris.

Stigler, M. (2011). Commodity prices : Theoretical and empirical properties. In Safeguarding food security in volatile global markets, FAO, United Nations, (pp. 25-41). Edited by Prakash, A.

Trivedi, P. K., \& Zimmer, D. M. (2007). Copula modeling: An introduction for practitioners, Foundations and Trends R in Econometrics. Now Publishers Inc. Boston.

Wang, Y., Wu, C., \& Yang, L. (2014). Oil price shocks and agricultural commodity prices. Energy Economics, $44,22-35$. https://doi.org/10.1016/j.eneco.2014.03.016

Zilberman, D., Hochman., G., Rajagopal, D., Sexton, S., \& Timilsina, G. (2013). The impact of biofuels on commodity food prices: Assessment of findings. American Journal of Agricultural Economics, 95(2), 275-281. https://doi.org/10.1093/ajae/aas037

Zivot, E., \& Wang, J. (2005). Modelling financial time series with S-PLUS ( ${ }^{\text {nd }}$ Edition). Springer.

\section{Copyrights}

Copyright for this article is retained by the author(s), with first publication rights granted to the journal.

This is an open-access article distributed under the terms and conditions of the Creative Commons Attribution license which permits unrestricted use, distribution, and reproduction in any medium, provided the original work is properly cited. 